\title{
Regulation of alveolar macrophage death in acute lung inflammation
}

\author{
Erica K Y Fan ${ }^{1}$ and Jie Fan $^{2,3,4^{*}}$ (D)
}

\begin{abstract}
Acute lung injury (ALI) and its severe form, known as acute respiratory distress syndrome (ARDS), are caused by direct pulmonary insults and indirect systemic inflammatory responses that result from conditions such as sepsis, trauma, and major surgery. The reciprocal influences between pulmonary and systemic inflammation augments the inflammatory process in the lung and promotes the development of ALI. Emerging evidence has revealed that alveolar macrophage (AM) death plays important roles in the progression of lung inflammation through its influence on other immune cell populations in the lung. Cell death and tissue inflammation form a positive feedback cycle, ultimately leading to exaggerated inflammation and development of disease. Pharmacological manipulation of AM death signals may serve as a logical therapeutic strategy for ALI/ARDS. This review will focus on recent advances in the regulation and underlying mechanisms of AM death as well as the influence of AM death on the development of ALI.
\end{abstract}

Keywords: Acute lung injury, Macrophages, Cell death, Pyroptosis, Necroptosis, Autophagy

\section{Background}

Regulated cell death is critical for the development and maintenance of an organism. In the 1970s, apoptosis was noted as "the only form of regulated cell death" [1-3]. As the field developed and progressed, a variety of regulated cell deaths were characterized, and depending on the signaling pathways involved, these different types of cell death resulted in either lytic or non-lytic morphology [4]. For example, apoptosis $[3,5]$ is a non-lytic and usually non-immunogenic form of cell death; whereas, necroptosis [6-8], pyroptosis [9], and NETosis [10] are lytic and highly inflammatory. In host defense, cell death can be used defensively, reducing infections by separating unaffected cells from infected cells; however, cell death can also increase inflammation.

The lung is one of the most important target organs for pro-inflammatory mediators secreted and released globally during sepsis [11] and trauma [12-14]. These severe pathologies are often followed by the development of acute lung injury (ALI) and acute respiratory distress syndrome (ARDS), which are characterized by

\footnotetext{
*Correspondence: jif7@pitt.edu

${ }^{2}$ Department of Surgery, University of Pittsburgh School of Medicine,

Pittsburgh, PA 15213, USA

${ }^{3}$ Research and Development, Veterans Affairs Pittsburgh Healthcare System,

Pittsburgh, PA 15240, USA

Full list of author information is available at the end of the article
}

pulmonary infiltrates, hypoxemia, and injury to both the vascular endothelium and lung alveolar epithelium. Alveolar macrophages (AM) account for approximately 95\% of airspace leukocytes [15], and through the synthesis and release of various inflammatory mediators, AM critically influence the development of ALI following infection and non-infectious stimuli [16, 17]. It is now clear that AM and other immune cells work in concert in the regulation of lung inflammation [18]. For example, while sepsis and trauma can lead to ALI and ARDS, equally, pulmonary infection and diffuse injury can cause systemic inflammatory response syndrome (SIRS), sepsis, and even septic shock [19]. These clinical syndromes lead to significant morbidity and mortality in intensive care units [20] and underscore the interplay between pulmonary and systemic inflammation in promoting disease progression.

Emerging evidence has revealed that AM cell death plays important roles in influencing the progression of lung inflammation [21-23]. There is increasing recognition that inflammation and cell death reciprocally affect each other and form an auto-amplification loop of these two factors, which in turn exaggerates inflammation [24]. Therefore, pharmacological manipulation of AM death signals may potentially serve as a logical therapeutic strategy for ALI/ARDS. This review will 
focus on recent advances in the regulation of AM death and underlying mechanisms as well as the influence of AM death on the development of acute lung inflammation.

\section{Alveolar macrophage Pyroptosis}

Pyroptosis is a form of regulated cell death that is both inflammatory and immunogenic. Cell pyroptosis protects multicellular organisms from invading pathogenic microbial infections; however, pyroptosis can cause local and systemic inflammation and even lead to lethal septic shock [25]. Pyroptosis is dependent on the activation of caspase- 1 or caspase $11 / 4 / 5$, which cleaves gasdermin D (GSDMD), a member of a family of conserved proteins that includes gasdermin A,B,C,D, E, and DFNB59 [26], most of which have been shown to have poreforming activity. Cleavage of GSDMD leads to the separation of its $\mathrm{N}$-terminal pore-forming domain (PFD) from the C-terminal repressor domain followed by PFD oligomerization and formation of large pores in the cell plasma membrane, causing cell swelling and membrane rupture. As such, pyroptosis is defined as a gasdermin-mediated regulated necrosis [25, 26].

The inflammasome, a protein complex that activates caspase- 1 and the secretion of cytokines IL- $1 \beta$ and IL18 , is one of the machineries that promote pyroptosis. The inflammasome is composed of sensor molecules, i.e. Nod-like receptor (NLRP1, 3, 6, 7, 12, NLRC4), AIM2, or Pyrin, in addition to an adaptor molecule apoptosisassociated speck-like protein containing CARD (ASC) and procaspase- $1[27,28]$. Procaspase- 1 associates with the ASC focus via CARD-CARD interactions, which leads to dimerization and proximity-induced proteolytic processing of procaspase- 1 into two subunits, p10 and p20, thus activating caspase- 1 . Activated caspase- 1 further cleaves pro-IL-1 $\beta$, pro-IL-18, and GSDMD. Normally, inflammasome formation requires a canonical two-step mechanism. Taking the NLRP3 inflammasome as an example, the first signal (e.g. stimulation of TLR4 or another pattern recognition receptor) stimulates NFkappa $\mathrm{B}$ and enhances the expression and synthesis of NLRP3; the second signal induces NLRP3 inflammasome assembly. Common second signals include binding of P2X purinoreceptor 7 (P2X7R) by adenosine triphosphate (ATP), $\mathrm{K}^{+}$efflux, lysosome destabilization caused by urate crystals, and generation of DNA and reactive oxygen species (ROS) in the mitochondria $[29,30]$.

Franklin et al. have shown that ASC foci that collect in the extracellular space following pyroptosis can promote IL-1 $\beta$ maturation [31]. Macrophage phagocytosis of ASC foci provokes lysosome rupture, soluble ASC nucleation, and the cleavage of IL-1 $\beta$ in the recipient cells [31]. These observations suggest an important mechanism, in which inflammasomes released from pyroptotic cells act as danger signals to amplify macrophage inflammatory responses.

IL-1 $\beta$ is an important proinflammatory cytokine that stimulates leukocyte expression of various cytokines and chemokines and leukocyte migration into tissue and organs [32]. IL-18 induces IFNY expression and secretion and is critical for the activation of macrophages, T-cells, and other immune cells [33]. It has been reported that cell lysis suppressed by pharmacological inhibitors did not prevent caspase-1-dependent pore formation on the plasma membrane and cytokine release, suggesting that release of IL-1 $\beta$ and IL-18 is not a cell lysis-dependent process, whereas, cell lysis and cytokine secretion are both consequent downstream events following caspase1-dependent plasma membrane pore formation [34]. Caspase-1-dependent pyroptosis may not occur in all cell types. For example, caspase- 1 activation in epithelial cells prevents cell pyroptosis through stimulating membrane repair function as a response to the membrane damage caused by pore-forming toxins aeroly$\sin$ and $\alpha$-toxin [35].

A recent study explored the role of LPS-activated IL$1 \beta$ release and IL-1RI upregulation in the progression of lung injury in the context of AM pyroptosis [36]. The study showed that in AM, LPS acting through TLR4MyD88-NF-kB dependent signaling stimulates Nlrp3 inflammasome activation and consequent secretion of IL-1 $\beta$. Importantly, LPS upregulates IL-1RI surface expression on AM, which sensitizes AM to IL- $1 \beta$ and results in pyroptosome formation and subsequent $\mathrm{AM}$ pyroptosis. Furthermore, the study demonstrated that AM pyroptosis aggravates lung inflammatory responses (Fig. 1) [36]. The data reveals a new mechanism by which LPS-activated upregulation of IL-1RI signaling promotes AM pyroptosis and amplifies lung injury.

ALI often occurs in post-hemorrhagic shock (HS) conditions. HS, as a result of major trauma or surgery, primes for ALI by exaggerating innate immune cell activation. Studies have shown that HS induces IL-1 $\beta$ expression and secretion, which in turn promotes the development of SIRS [37-43]. Regarding how HS enhances IL-1 $\beta$ expression, activation, and release from AM, LPS, while activating Nlrp3 inflammasomes in AM, also induce pyrin expression, which in turn suppresses inflammasome activation [44]. Pyrin, a 781 amino-acid protein, is a vital regulator of the inflammasome [45]. The $\mathrm{N}$-terminal of pyrin constitutes a pyrin domain (PYD), a member of the death effector-fold domain $[46,47]$. The PYD found in pyrin is also present in the nucleotidebinding oligomerization domain-like receptor protein (NLRP; the nomenclature used in mouse is Nlrp). Importantly, LPS-mediated upregulation of IL-10 enhances pyrin expression, which, particularly in later phases of inflammation, serves as a potent negative feedback mechanism 


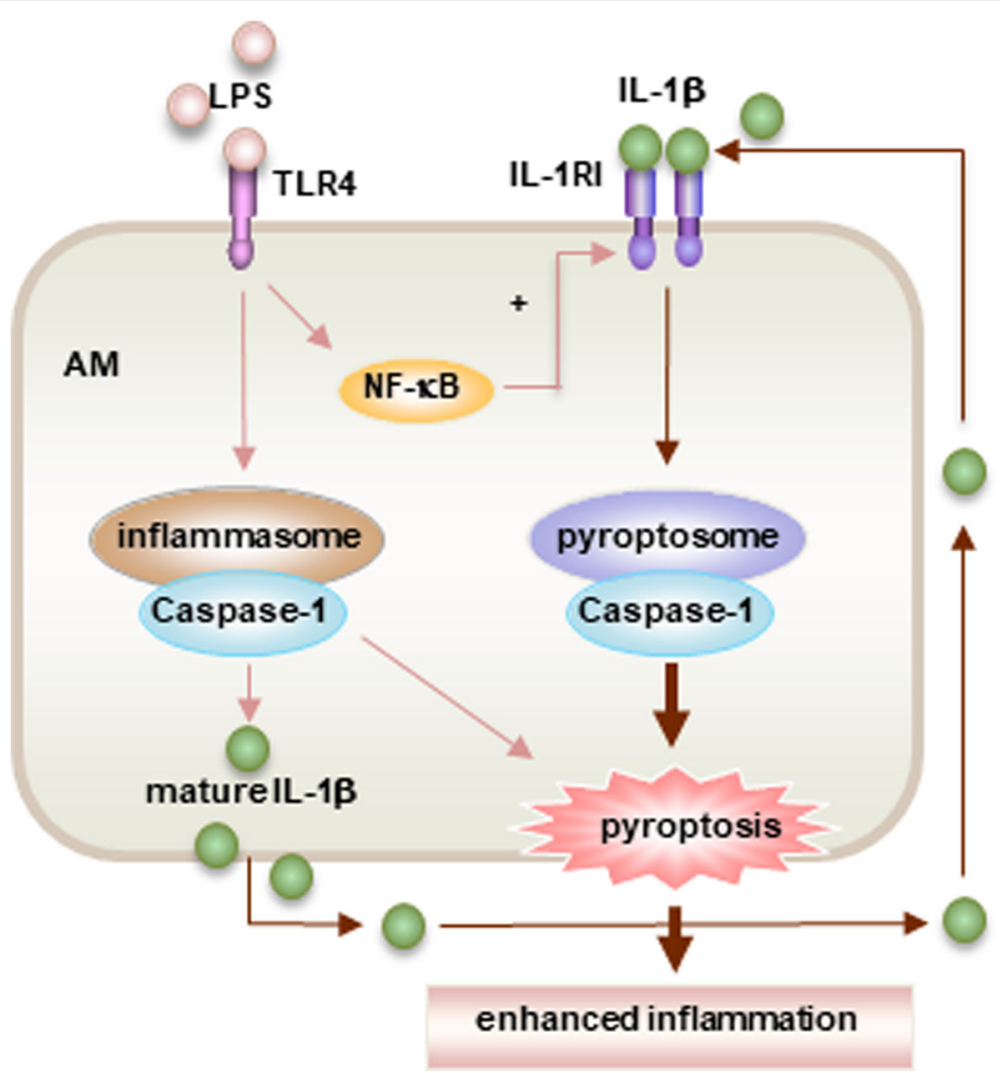

Fig. $1 \mathrm{IL}-1 \beta-I L-1 R I-m e d i a t e d e d$ AM pyroptosis and lung inflammation in response to LPS. In AM LPS-TLR4 signaling not only activates Nlrp3 inflammasome activation and subsequent release of IL-1 $\beta$, but also up-regulates IL-1RI cell surface expression through MyD88 and NF-KB dependent signaling. The upregulated IL-1RI, therefore, sensitizes AM to IL-1 $\beta$ and results in pyroptosome activation, which in turn leads to AM pyroptosis, a type of caspase-1-dependent inflammatory cell death, and subsequent exaggerated lung inflammation (This figure is adapted from the Ref. [36]. Adapted with permission)

to regulate inflammasome activation. However, HSmediated suppression of IL-10 expression in AM attenuates the upregulation of pyrin in AM and lung endothelial cells, and therefore significantly enhances inflammasome activation and IL-1 $\beta$ secretion in the lungs. This study demonstrates a mechanism by which HS suppresses negative feedback regulation of the Nlrp3 inflammasome to enhance IL-1 $\beta$ secretion in response to subsequent LPS challenge, and thus primes the host for inflammation [44].

HS also sensitizes AM responses to bacterial products through upregulating pattern recognition receptor (PPR) expression in AM $[48,49]$. Previous studies have shown that HS-activated neutrophils plays an important role in AM priming, particularly, in mediating TLR4 and TLR2 crosstalk in AM [48]. The study demonstrated with a mouse model of HS followed by intratracheal injection (i.t.) of LPS that HS augments LPS upregulation of TLR2 expression in AM through activation of IL-1 receptor associated kinase 4 (IRAK 4) $[49,50]$. However, in mice with neutrophils depletion, HS/LPS-upregulated TLR2 expression was markedly decreased, and this decrease was reversed upon replenishment with neutrophils collected from HS mice, but not from sham-operated mice. Furthermore, the study demonstrated that reactive oxygen species (ROS) derived from neutrophil NADPH oxidase mediates TLR4-TLR2 crosstalk in AM. The enhanced TLR2 upregulation in AM augmented the AM inflammatory response to sequential stimulations of LPS and peptidoglycan (PGN), a TLR2 ligand. These results indicate that TLR4-upregulated TLR2 expression in AM, which is enhanced by HS-activated neutrophils, serves as an imperative positive-feedback mechanism underlying HS-primed activation of AM $[49,50]$.

Inflammasome activation can be bypassed in macrophage pyroptosis formation induced by high mobility group box 1 (HMGB1). HMGB1, a ubiquitous nuclear protein that exists in virtually all cell types, is a damageassociated molecular pattern (DAMP) molecule [51-53]. HMGB1 is released from cells following infection and tissue injury and is a crucial inflammatory mediator to induce a range of cellular responses, which include cell chemotaxis and release of pro-inflammatory cytokines 
[54, 55]. HMGB1 binding to its cell surface receptors, including TLR2, TLR4, TLR9 and the receptor for advanced glycation end products (RAGE) is necessary for initiating inflammatory responses $[52,53]$. We have reported an inflammasome-independent mechanism by which HMGB1 induces AM pyroptosis [21]. We demonstrated that HMGB1 binds to RAGE on AM and elicits HMGB1 endocytosis, a dynamin-required event, followed by a cascade of molecular events, which include cathepsin $\mathrm{B}$ (CatB) activation and release from lysosomes, and ACS foci (also known as pyroptosome) formation and caspase1 activation (Fig. 2). These findings were further confirmed in an endotoxemia mouse model, suggesting pathological implications for AM pyroptosis in the progression of inflammatory responses [21].

Infection and trauma through release of pathogenassociated molecular pattern molecules (PAMPs) and DAMPs, respectively, activate inflammasomes [56, 57], which in turn may initiate cell necroptosis. Cullen et al. demonstrated that inflammasome activation is associated with "conventional necrosis" and that the necrotic plasma membrane permeabilization (PMP) allows for the efflux of $\mathrm{K}^{+}$ions required for NLRP3 activation, as well as for the unspecific release of IL-1 $\beta$ [58]. Martín-Sánchez and colleagues [59] also reported that bee venom antimicrobial toxin peptide melittin, which is known to elicit an inflammatory reaction via the NLRP3 inflammasome in response to bee venom, induces canonical NLRP3 inflammasome activation by PMP and a reduction in the intracellular $\mathrm{K}^{+}$concentration. This NLRP3 inflammasome requires the adaptor protein ASC to activate caspase-1 and induce IL-1 $\beta$ release; however, melittin is unable to induce large ASC aggregates. Melittin-induced PMP and subsequent cell death was independent of caspase-1, showing that rapid cell lysis driven by melittin excludes pyroptosis execution by caspase-1. These studies suggest that inflammasome activation and subsequent caspase-1 activation are not necessarily to induce pyroptosis, but lead to cell necroptosis, although how the signal elicits necroptosis pathway remains unclear.

Studies have shown that AM pyroptosis augments lung inflammation in response to intratracheal administration of LPS. AM pyroptosis promotes neutrophil migration into the lungs and increases alveolar concentrations of cytokines IL- 6 , TNF $\alpha$, and IL-1 $1 \beta$, and worsen histological manifestations of lung injury [36]. Thus, targeting AM pyroptosis may represent a therapeutic strategy for controlling lung inflammation.

\section{Alveolar macrophage necrosis and necroptosis}

Traditionally, necrosis was viewed as an accidental subroutine, mostly resulting from very harsh physicochemical

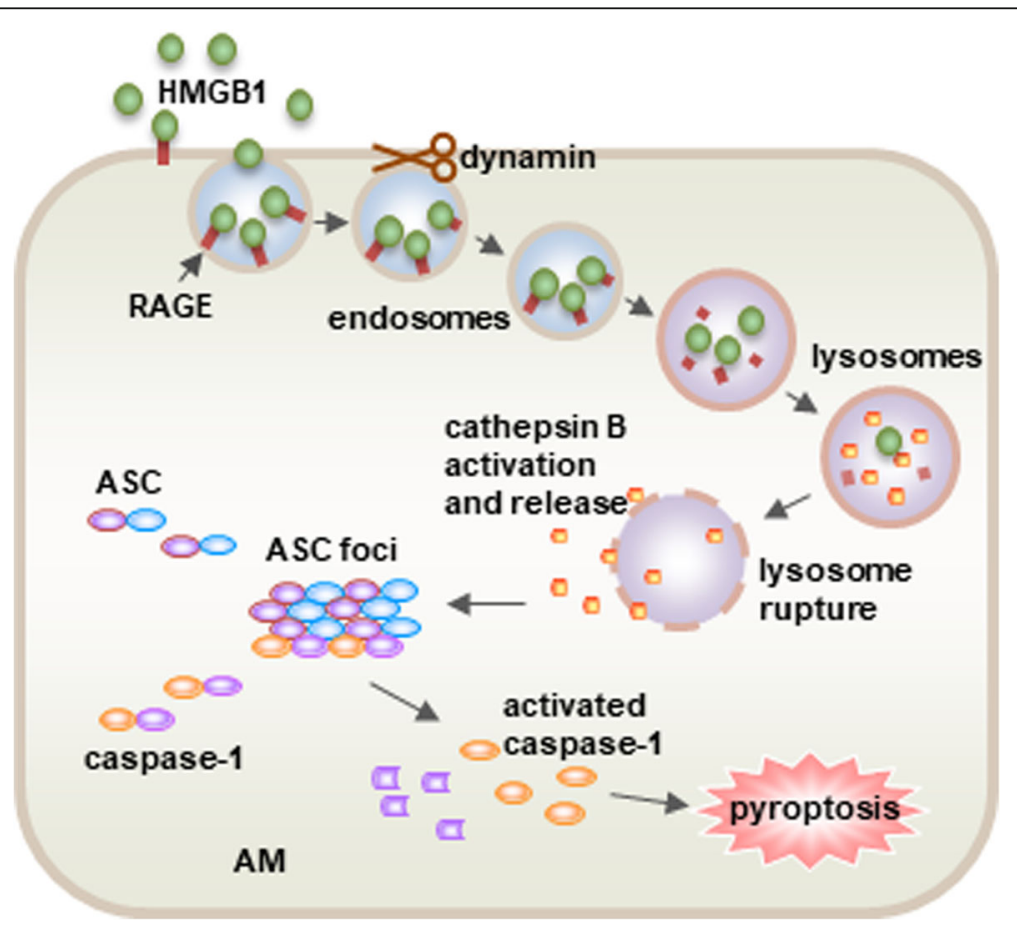

Fig. 2 Endocytosis of HMGB1 induces pyroptosis. HMGB1 acting through RAGE on macrophages triggers dynamin-dependent endocytosis of HMGB1, which in turn initiates a cascade of cellular and molecular events. These include CatB activation and release from ruptured lysosome followed by pyroptosome formation and caspase-1 activation, which serves as a mechanism underlying the HMGB1-induced pyroptosis (This figure is adapted from the Ref. [21]. Adapted with permission) 
stimuli including abrupt changes in temperature, osmotic pressure, or $\mathrm{pH}$ [60]. However, recent evidence has shown that necrosis can also occur in a regulated manner called necroptosis. Necroptosis is regulated by a receptorinteracting protein kinase (RIPK)1-RIPK3 complex dependent pathway, and it is negatively regulated by Necrostatin-1 (Nec-1) [61]. Since AM necrosis initiated in inflammation is usually in a regulated form, we will use the term of AM necroptosis in this section. The class of death receptors that includes tumor necrosis factor receptor (TNFR)1, TNFR2, and Fas can induce necroptosis. Binding of TNF- $\alpha$ to TNFR1 causes dissociation of silencer of death domains (SODD) from the intracellular domain of TNFR1 [62], followed by complex I formation. Complex I is composed of TNFR1 and TNFR2, TNFRassociated death domain, Fas-associated death domain (FADD), RIPK1, E3 ubiquitin ligases, and inhibitor of apoptosis proteins (IAPs) cIAP1 and cIAP2 [63]. The downstream effects of RIPK1 depend on its ubiquitination state, thus positioning complex I at the crossroads of cell death and survival. Deubiquitination of RIPK1 suppresses the NF- $\kappa B$ pathway, which leads to cell death. TNFR1 activation with no integration of c-IAPs (e.g. with the treatment of IAP antagonists), or with inhibition of translation, or with deubiquitination of RIPK1 by the deubiquitinating enzyme CYLD may induce RIPK1 translocation to a secondary complex in the cytoplasm called complex II [64-66]. Complex II is composed of caspase-8, the death domain containing protein FADD, and cellular FADD-like IL-1 $\beta$-converting enzyme-inhibitory protein. Activation of caspase- 8 induces cleavage of RIPK1 and RIPK3 and promotes complex II into a pro-apoptosis state. Conversely, inhibition of the apoptosis pathway drives the formation of necrosomes, which are mainly composed of RIPK 1 and RIPK3 and functions to promote necroptosis [67].

Noteworthy, the above described necroptosis signaling was explored mostly in cancer cell lines and Jurkat lymphocyte cells other than macrophages. Whether the necroptosis signaling is also valid in macrophages, or more particularly in AM, remains to be determined.

The pseudokinase mixed lineage kinase domain-like (MLKL) protein is a RIPK3 substrate and is required for necroptosis [68, 69]. MLKL recruitment and phosphorylation is caused by RIP homotypic interaction motif (RHIM)-dependent oligomerization and intra-molecular RIPK3 auto-phosphorylation [70, 71], which leads to induction of cell necroptosis [72]. Additionally, studies have reported that MLKL oligomerization induced by RIPK3 and its subsequent translocation to the plasma membrane is associated with its cytotoxic effects [73-76]: MLKL can precipitate plasma membrane rupture by binding to phosphatidylinositol phosphates (PIPs) [73, 75], causing changes in sodium and calcium influx through ion channels and consequently causing changes in intracellular osmotic pressure [74, 76, 77].

The mechanisms determining if a cell dies by apoptosis or necroptosis remain poorly understood [78]. Several studies suggest that expression levels of RIPK3 and MLKL are associated with the tendency for cells to undergo necroptosis [78-84]. Some studies suggest that catalytically inactive RIPK3 trends to lead to RIPK1dependent apoptosis, whereas catalytically active RIPK3 induces necroptosis [85]. On the other hand, caspase-8 is the most important molecule that prevents necroptosis. Studies show that necroptosis can be achieved in vivo by a genetic defect compromising FADD-caspase- 8 signaling, thus inhibiting apoptosis [86-89]. More studies, particularly, in vivo studies, are required to understand the mechanisms that determine the susceptibility of macrophages to necroptosis or apoptosis.

Some reports have demonstrated that RIPK1 can inhibit apoptosis and necroptosis through kinase-independent functions, which are important for late embryonic development and the prevention of inflammation in epithelial barriers [82, 90-93]. Lin and colleagues showed that RIPK1 prevents skin inflammation by inhibiting activation of RIPK3-MLKL-dependent necroptosis mediated by ZDNA binding protein 1 (ZBP1, also known as DAI or DLM1) [94]. The Lin group showed that ZBP1 deficiency inhibited keratinocyte necroptosis and skin inflammation in mice with epidermis specific RIPK1 knockout. Mechanistically, ZBP1 interacted strongly with phosphorylated RIPK3 in cells expressing the conserved RHIM of endogenous mouse RIPK1 (RIPK1 RHIM), suggesting that the RIPK1 RHIM prevents ZBP1 from binding and activating RIPK3. Newton et al. reported that RIPK1 RHIM is also critical for preventing ZBP1/RIPK3/ MLKL-dependent necroptosis during development [95]. However, future studies will need to address if the RIPK1 RHIM also plays an important role in the regulation of AM necroptosis in ALI.

Severe trauma often causes organ failure including ALI, in which AM play a critical role in the development of inflammation. Our group has recently reported a cold-inducible RNA-binding protein (CIRP)-mediated mechanism, by which trauma regulates AM death [96]. CIRP belongs to the cold shock protein family [97], and contains 172 amino acid residues (95\% identical between human and mouse CIRP) that form a consensus sequence of N-terminal RNA-binding domain and Cterminal glycine-rich domain of nuclear proteins, which serve as RNA chaperones facilitating RNA translation $[98,99]$. Studies have shown that CIRP is a DAMP molecule expressed during shock and trauma [100, 101], and it provokes a range of cellular inflammatory responses from inflammatory cytokines release to endothelial cell dysfunction [23]. We found that CRIP 
released from damaged tissue acts through TLR4 and MyD88-dependent signaling to induce mitochondrial DNA (mtDNA) fragmentation in AM [96]. This is achieved by ROS (particularly those originated from $\mathrm{NADPH}$ oxidase), which serve as key mediators of endonuclease G activation, which, in turn, directly regulates mtDNA fragmentation. Fragmented mtDNA then prompts AM autophagy and necroptosis via separate signaling pathways. Interestingly, autophagy suppresses AM necroptosis, thereby attenuating the propagation of local inflammation (Fig. 3) [96]. This study demonstrates an intracellular regulation of macrophage homeostasis in response to trauma.

The regulation of AM necroptosis is more complicated than previously thought, especially when multiple conditions, i.e. trauma and infection, exist simultaneously. Tissue damage resulting from severe trauma and surgery often results in either infection or heightened susceptibility to infection. The reciprocal influences between tissue damage and infection are considered to be a determinant in regulating the host's inflammatory responses. The role of trauma and tissue damage in the regulation of LPS-induced AM necroptosis and the underlying mechanism has been examined [22]. The studies demonstrated that LPS-TLR4 signaling promotes AM necroptosis; however, necroptosis is ameliorated by the release of HMGB1 from damaged tissue. The study further showed that HMGB1 binds to its receptor RAGE to promote upregulation of caveolin-1 expression, which induces caveolae-dependent TLR4 internalization and desensitization, and ultimately decreases AM necroptosis. Furthermore, the study illustrated that the activation of transcription factor Sp1 by the RAGE-MyD88-Cdc42 signaling pathway is a mechanism that mediates caveolin-1 transcriptional upregulation (Fig. 4) [22].

It has been reported that a precedent trauma often primes for augmented inflammatory responses to infection and bacterial products through the release of DAMPs [37, 44, 48, 102, 103]. As described above, studies have shown that tissue damage-derived CIRP alone is able to induce AM necroptosis through mtDNA fragmentation [96]. Those results suggested that inhibition of DAMP signaling may diminish inflammatory responses to a secondary infection. However, the finding that tissue damage negatively regulates LPS-induced AM necroptosis through DAMP signaling unveils a feedback mechanism that attenuates the inflammatory response to a secondary LPS challenge. These results expose a previous unidentified protective role of DAMP molecules in limiting PAMP molecules-induced inflammation [22].

Studies have shown the effects of necroptosis on the development of systemic inflammation. In animal model

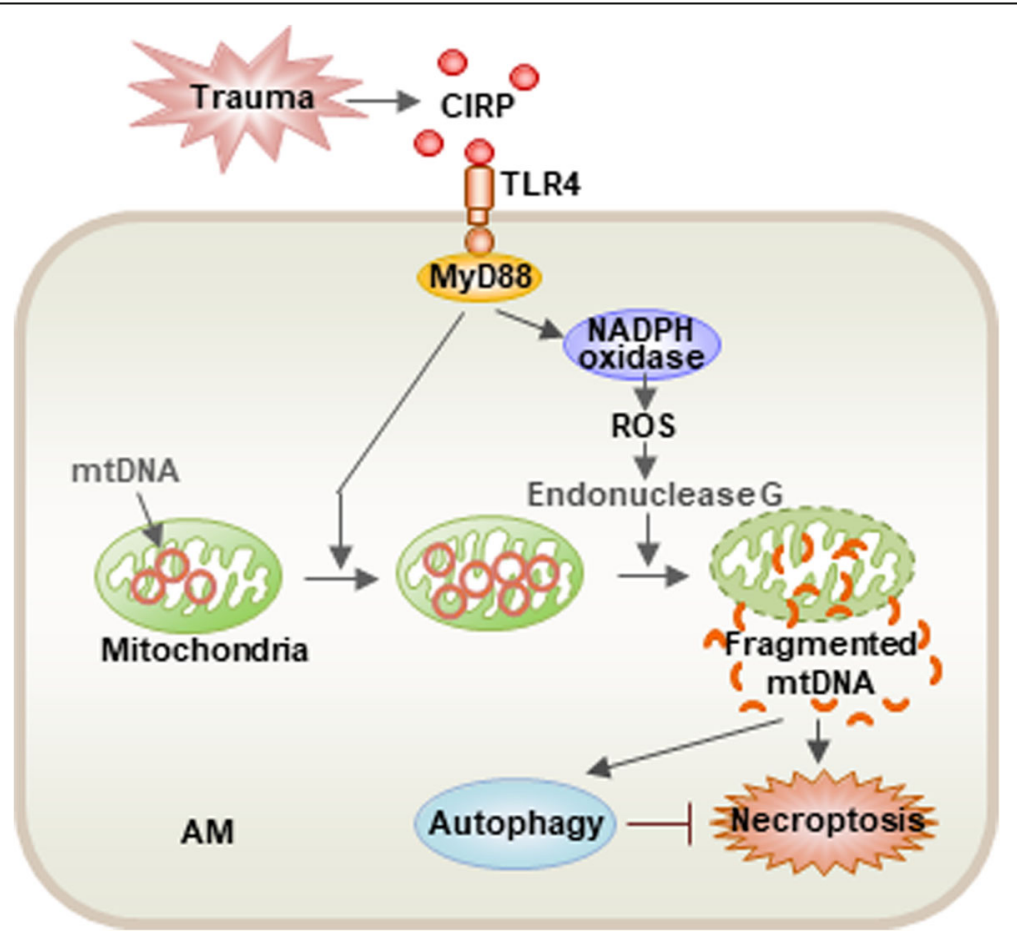

Fig. 3 Trauma-induced mtDNA fragmentation regulates macrophage death. Trauma through CIRP-TLR4-MyD88 signaling induces NADPH oxidase activation and release of ROS, which activate endonuclease G. Endonuclease G directly fragments mtDNA, which triggers macrophage autophagy, as well as necroptosis by separate pathways. However, autophagy also suppresses macrophage necroptosis to limit local inflammation (This figure is adapted from the Ref. [96]. Adapted with permission) 


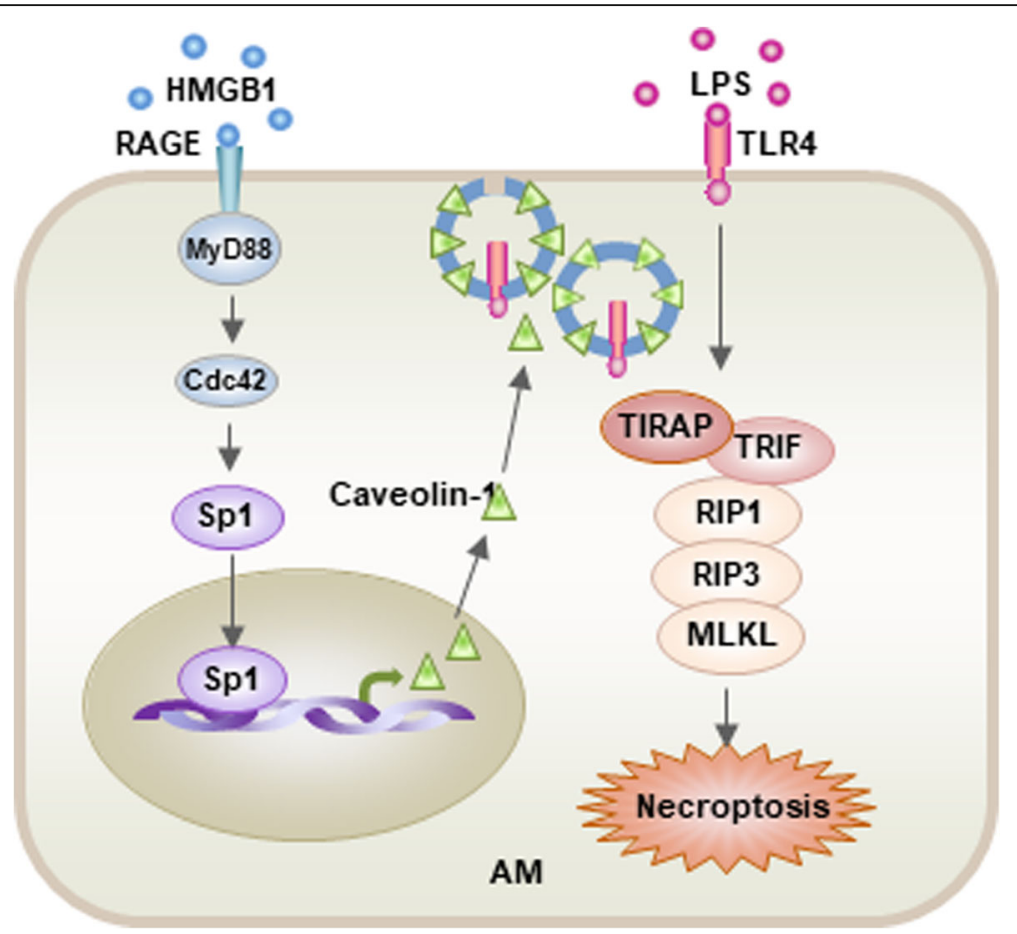

Fig. 4 Model of the mechanism underlying tissue damage regulation of LPS-induced macrophage necroptosis. LPS acting through TLR4 promotes macrophage necroptosis. However, damaged tissue through HMGB1/RAGE signaling upregulates caveolin-1 expression in macrophage, which, in turn, induces caveolae-mediated TLR4 internalization and desensitization, thereby, ameliorates LPS-TLR4-induced macrophage necroptosis. RAGE-MyD88 signal activation of Cdc42 and the consequent nuclear translocation of Sp1 serve the mechanism of upregulation of caveolin-1 (This figure is adapted from the Ref. [22]. Adapted with permission)

of septic shock, RIPK3 deficiency prevents the remarkable increase in circulating cell death markers and promotes survival [104], suggesting that targeting RIPK3 in sepsis might be beneficial. Interestingly, caecal ligation puncture-mediated lethality was not restored in $\mathrm{Mlkl}$ knockout mice [105], suggesting that the functions of RIPK3 and MLKL may not completely overlap in this context [106]. In a model of TNF-induced SIRS, pretreatment with necrostatin-1 or Nec-1 s strongly inhibited lethality [107], and this finding was supported by studies showing that RIPK1 kinase-inactive mice are also resistant to the lethality of TNF-induced SIRS and to the lethality of septic shock induced by a combination of TNF and Z-VAD-FMK [106, 108, 109]. Together, these data suggest that RIPK1 and RIPK3 inhibitors might be effective in treating SIRS and related diseases by targeting not only necroptosis but also other pro-inflammatory conditions regulated by these kinases [106].

\section{Alveolar macrophage autophagy}

Autophagy is an evolutionarily conserved and genetically regulated pathway that serves to degrade and clear subcellular components [110, 111]. Autophagy was previously classified as a caspase-independent necrosis-like cell death associated with intracellular autophagosomes accumulation [112]. However, the causal relationship between autophagy and cell death has yet been to be defined, and thus, this classification remains controversial [113, 114].

The dynamic autophagic process is mainly implemented by a series of proteins, encoded by the autophagy related genes (ATGs). ATG proteins work in concert to dynamically promote formation of pre-autophagosome, maturation of autophagosome, and fusion with lysosome. The core machinery of autophagy, consisting of the ATGs, is regulated by many signaling pathways such as the mechanistic target of rapamycin (mTOR) pathway, the insulin pathway, and the ER stress response [115] . The signals that induce and regulate autophagy activation are still not fully elucidated. Since numerous review articles about autophagy basics are available [115-117], we will only focus on recent findings on the regulation and functions of AM autophagy in this review.

Autophagy can be activated by PRR signaling induced by DAMPs and PAMPs. For example, PAMPs can act through TLRs to induce autophagy [118, 119], and NLRs can cooperate with ATGs to confine autophagy [120, 121]. Inflammatory cytokines, including IL-1 family members $[122,123]$ and IFN $\gamma$ [124-126], also promote autophagy; 


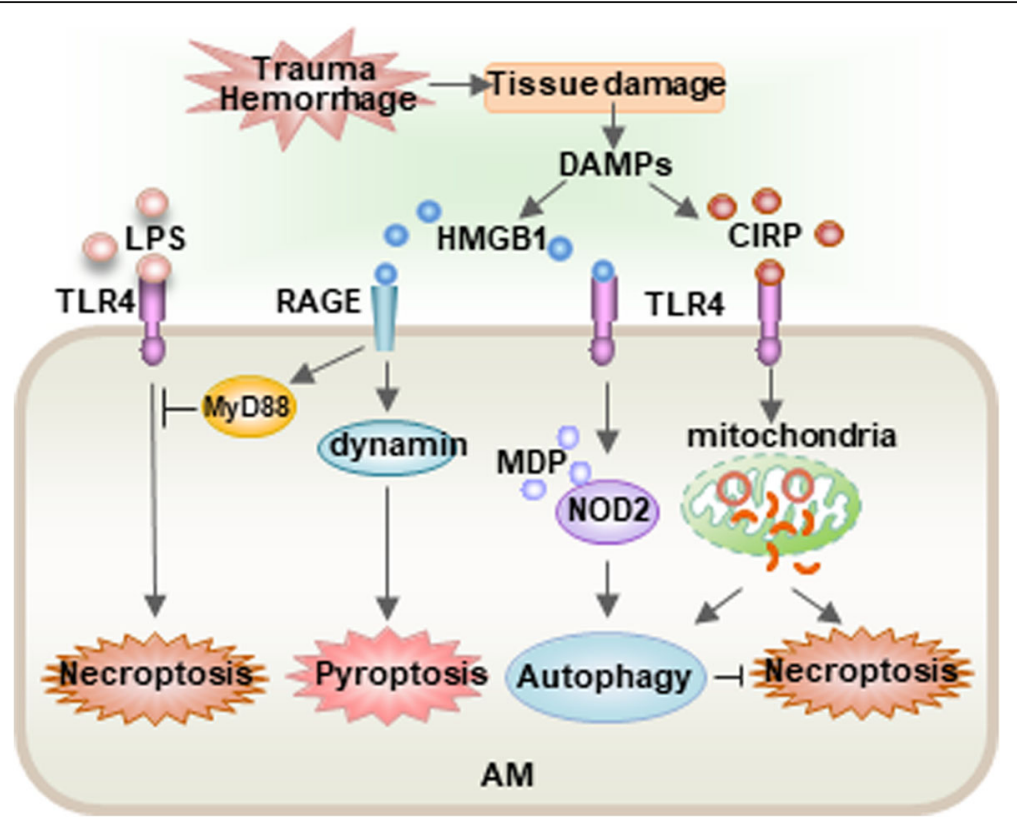

Fig. 5 The complexity of AM death Regulation following infection, trauma, and HS. LPS, an important PAMP molecule derived from Gram negative bacteria acting through TLR4 promotes AM necroptosis. However, DAMP molecules released from tissue damage, which is a resultant of severe trauma and HS, significantly influence the regulation of AM death. For example, DAMP molecule HMGB1 acting through cell surface RAGE and MyD88-dependent pathway (as illustrated in Fig. 3) ameliorates the TLR4-mediated AM necroptosis. On the other aspect, HMGB1triggers RAGE-dynamin-dependent endocytosis of HMGB1, which promotes AM pyroptosis. HMGB1/TLR4 signaling upregulates NOD2 expression in AM and sensitizes them to subsequent NOD2 ligand MDP to induces autophagy in AM, which negatively regulates lung inflammation through feedback suppression of NOD2-RIP2 signaling and inflammasome activation. DAMP molecule CIRP acts through TLR4-MyD88 signaling to induce mtDNA fragmentation in AM, via a pathway in which NADPH oxidase-derived ROS served as a major mediator for the induction of endonuclease $G$, which, in turn, directly mediates mtDNA fragmentation. Fragmented mtDNA then triggered AM autophagy and necroptosis through separate signaling pathways, although autophagy also suppressed AM necroptosis, to attenuate propagation of local inflammation. Therefore, AM autophagy represents an intracellular negative regulation of AM death, whereas, pyroptosis serves as a dominant AM death form in a condition combined with infection, trauma and hemorrhage

conversely, $\mathrm{T}_{\mathrm{H}} 2$ cell-associated cytokines, i.e. IL-4 and IL13, inhibit autophagy [125]. Many studies have shown that autophagy protects organisms from infection by degrading intracellular pathogens, i.e. bacteria, viruses, and protozoan pathogens, demonstrating an important role of autophagy in host defense [127-129].

Our study explored a previously unidentified function of neutrophils in counteracting the AM intracellular anti-inflammatory mechanism of autophagy [103]. In a HS mouse model, we demonstrated that sequential treatment of HS and intratracheal injection of muramyl dipeptide (MDP), a NOD2 ligand, activates HMGB1-TLR4 signaling in AM, which upregulates NOD2 expression and sensitizes the AM to MDP, and therefore amplifies lung inflammation [103]. Additionally, upregulated NOD2 signaling promotes autophagy formation in AM, which suppresses lung inflammation through the downregulation of NOD2-RIP2 signaling, as well as NLRP3 inflammasome activation. Importantly, the study also demonstrated that shock-activated neutrophils migrate into the alveolar space to counteract the anti-inflammatory effect of autophagy in AM through an NADPH oxidase-dependent pathway that induces $I K K \gamma$ phosphorylation, NF-KB activation, and NLRP3 inflammasome activation, consequently augmenting post-HS lung inflammation. These findings suggest an important role for receptor cross-talk and cell-cell interaction in the complicated mechanisms of ALI [103].

A recent study revealed a suppressive role of autophagy in AM apoptosis in the early stages of hypoxia [130]. Geng group reported that, using a cell hypoxia-reoxygenation model and rat orthotopic left lung ischemia-reperfusion model, rapamycin decreases the unfolded protein response, which reduces endoplasmic reticulum stressmediated apoptosis in the presence of oxygen deficiency. Rapamycin increases superoxide dismutase activities and decreases malondialdehyde levels, whereas 3-MA decreases superoxide dismutase activities and increases malondialdehyde levels. Thus, the investigators concluded that autophagy decreases AM apoptosis by attenuating ER stress and oxidative stress in the early stage of hypoxia in vitro and in vivo [130].

Lung a post-ischemia-reperfusion (I/R) remains one of the most common complications after various cardiopulmonary 
surgeries. Liu and colleagues reported that, in a minipig lung $\mathrm{I} / \mathrm{R}$ injury model, left lung $\mathrm{I} / \mathrm{R}$ injury triggered release of DAMPs, such as HMGB1 and heat shock protein 60 (HSP60), in the lung and production of inflammatory cytokine and activation of autophagy flux in AM. However, autophagy inhibition by knockdown of ATG7 or BECN1 markedly reduced DAMP-triggered production of inflammatory cytokines including IL-1 $\beta$, TNF, and IL12 in AM, and these changes were a result of decreased activation of MAPK and NF- $\mathrm{kB}$ signaling. Furthermore, knockdown of ATG7 or BECN1 inhibited Lys63 (K63)-linked ubiquitination of TNF receptor-associated factor 6 (TRAF6) in DAMP-treated AM. These results indicate that autophagy triggered by DAMPs during lung $\mathrm{I} / \mathrm{R}$ injury amplifies the inflammatory response through enhancing K63-linked ubiquitination of TRAF6 and activation of the downstream MAPK and NF- $\mathrm{kB}$ signaling [131].

Autophagy's effect on the outcome of acute lung inflammation depends on the disease background, phase or stage of the progression of the lung inflammation, and the balance between inflammatory factors, including pro-inflammatory cell death and anti-inflammatory factors. Nonetheless, modulation of autophagy may serve as a potential therapy for ALI.

\section{Death signal interaction between alveolar macrophages and neutrophils}

Emerging evidence has revealed that neutrophils play important roles in influencing the behavior and functions of other cell types in the progression of lung inflammation. For example, we have reported that neutrophil-derived oxidants mediate the interaction between neutrophils and lung endothelial cells (LEC) and upregulate TLR2 expression in LEC via TLR4 signaling. Upregulation of TLR2 results in the stable and augmented expression of ICAM-1 in response to LPS and peptidoglycan, which then subsequently promotes transendothelial neutrophils migration into the lungs [132]. The above-mentioned finding that neutrophils counteract autophagy-mediated anti-inflammatory mechanisms in AM is another instance of neutrophil behavioral control [103].

Indeed, neutrophils are an active cell population with diverse functions and characteristics, including migration, phagocytosis, degranulation, secretion of cytokines, and release of ROS and enzymes; thus, neutrophils are thought to play an active role in inducing functional changes in other cell populations. Recent observations by our group have shown that this is a bidirectional relationship: following HS, AM in the alveolar space can target neutrophils to induce cell death [133]. Using hemorrhagic shock animal models, the study explored a previously unidentified role of hemorrhagic shockactivated AM in inducing neutrophil necroptosis. The study showed that exosomes released from hemorrhagic shock-activated AM cause neutrophils to produce ROS, primarily derived from NADPH oxidase, and consequently promote neutrophil necroptosis [133].

Exosomes are cell-derived secreted vesicles with a bilipid membranous structure. Exosomes are $30-100 \mathrm{~nm}$ in size and contain RNA, proteins, and lipids [134]. Most cells can secrete exosomes under normal conditions; however, under pathologic or stressful conditions, exosome quantity or content may be altered [135]. Reports suggest that exosomes mediate intercellular communication, stimulate target cells, promote antigen presentation, transfer pathogens, and regulate immune responses [136]. We found that exosomes released from HSactivated AM induce mainly NADPH oxidase-derived ROS production inside neutrophils and subsequent promotion of necroptosis [133]. These findings therefore add a new role for exosomes in mediating cell-cell crosstalk in HS. This exosomes-mediated neutrophil death pathway may be a potential therapeutic strategy to target post-HS SIRS.

It has been predicted that the pro-inflammatory cell death form of necroptosis is involved in disease pathogenesis since animal studies provided strong evidence for this hypothesis [137]. The migration of human neutrophils to inflammatory sites was found to activate the RIPK3-MLKL pathway in tissue samples from patients with neutrophilic diseases including cutaneous vasculitis, ulcerative colitis, and psoriasis [138]. However, the role of neutrophil necroptosis in human pathologies, especially in ALI, remains to be further identified [78, 139]. Thus, the question of how does neutrophil necroptosis impact on lung inflammation is still open.

\section{Conclusion}

The clinical and pathologic manifestations of ALI/ ARDS are very similar, indicating the existence of common pathways that represent potential therapeutic targets. Fundamentally, ALI/ARDS reflect severe injury leading to dysfunction and compromise of the barrier properties of the pulmonary endothelium and epithelium as a consequence of an unregulated acute inflammatory response. We are still lacking effective pharmacotherapy that can increase the survival of ALI/ARDS patients. Studies have provided evidence for a connection between cell death and lung inflammation, and understanding of the impact of AM death on the progression of lung inflammation is critical in fully elucidating the mechanisms underlying ALI/ARDS. However, by reviewing the literature, we found that reports derived from translational and clinical research on the mechanism of cell death in ALI/ARDS are insufficient, and thus, the translational and clinical research is expected. 
It is imperative to realize the therapeutic potential of targeting cell death pathways in ALI/ARDS patients. Following an initial event of inflammation, cell death and inflammation can induce each other and drive a local auto-amplification loop that leads to exaggerated cell death and inflammation [24]. Pharmacological inhibition of the autoamplification loop should ideally target the initial AM death, and thereby theoretically prevent the loop from developing. For instances, inhibitors could be used to prevent the AM necroptosis, such as Nec-1 [140, 141], Nec-1 s, Nec-33, and necrosulfonamide [142]; and to target pyroptosis, caspase inhibitors and inflammasome inhibitors, i.e. pralnacasan (VX-740; Vertex Pharmaceuticals) and belnacasan (VX-765; Vertex Pharmaceuticals) might be applied [143]. A combination therapy approach involving the use of such agents along with standard immunosuppression to further interfere with regulated cell death could also be considered [24].

Other forms of cell death that are also implicated in pathological settings but that are not discussed here include apoptosis, ferroptosis, parthanatos, NETosis, and CypD-mediated cell death. Apoptosis was long thought to be the only form of programmed cell death during homeostasis, development, and disease, and has been heavily studied and discussed in numerus review articles in literature. The gaps in our knowledge on cell death include the following: 1) whether different types of cell death signaling developed separately as responses to specific triggers or whether they represent parts of a signaling network that follow common regulatory mechanisms, such as energy devastation or ROS production; and 2) how these regulatory networks modulate shifts between different cell death routines [106]. As summarized in Fig. 5, the regulation of AM death is complex given the multitude of factors that simultaneously influence the pathway. Although we have accumulated knowledge on cell death, we are still a long way from a fully understanding of how these pathways converge or synergize in an ALI setting. Comprehensive understanding of the molecular mechanisms that regulate cell death will allow the development of strategies that control cell death, thereby developing novel interventions for ALI/ARDS.

\footnotetext{
Abbreviations

ALI: Acute lung injury; AM: Alveolar macrophage; ARDS: Acute respiratory distress syndrome; ASC: Apoptosis-associated speck-like protein containing CARD; ATGs: Autophagy related genes; CatB: Cathepsin B; CIRP: Coldinducible RNA-binding protein; DAMP: Damage-associated molecular pattern; FADD: Fas-associated death domain; GSDMD: Gasdermin D; P2X7R: P2XPurinoreceptor; HMGB1: High mobility group box 1; HS: Hemorrhagic shock; HSP60: Heat shock protein 60; IAPs: Inhibitor of apoptosis proteins; I/R: Ischemia-reperfusion; IRAK: 4 IL-1 receptor associated kinase 4; LEC: Lung endothelial cells; MDP: Muramyl dipeptide; MLKL: Mixed lineage kinase domain-like; mtDNA: Mitochondrial DNA; mTOR: Mechanistic target of rapamycin; NLRP: Nucleotide-binding oligomerization domain-like
}

receptor protein; PAMP: Pathogen-associated molecular pattern molecules; PMP: Plasma membrane permeabilization; PFD: Pore-forming domain; PGN: Peptidoglycan; PIPs: Phosphatidylinositol phosphates; PPR: Pattern recognition receptor; PYD: Pyrin domain; RAGE: Receptor for advanced glycation end products; RCD: Regulated cell death; RIPK: Receptor-interacting protein kinase; ROS: Reactive oxygen species; SIRS: Systemic inflammatory response syndrome; SODD: Silencer of death domains; TLR: Toll-like receptor; TNFR: Tumor necrosis factor receptor; TRAF6: TNF receptor-associated factor 6; ZBP1: Z-DNA binding protein 1

\section{Acknowledgements}

None

\section{Funding}

This work was supported by the National Institutes of Health Grant R01-HL079669 (J.F.), National Institutes of Health Grant R01HL076179-09 (J.F.), and VA Merit Award 1101BX002729 (J.F.).

\section{Availability of data and materials}

Not applicable (review article).

\section{Authors' contributions}

EF: researching data, preparation of the figures, writing and editing the manuscript. JF: conception, design, writing the manuscript, preparation of the figures. Both authors read and approved the final manuscript.

Ethics approval and consent to participate

Not applicable

Consent for publication

Not applicable

Competing interests

The authors declare that they have no competing interests.

\section{Publisher's Note}

Springer Nature remains neutral with regard to jurisdictional claims in published maps and institutional affiliations.

\section{Author details}

${ }^{1}$ Kenneth P. Dietrich School of Arts \& Sciences, University of Pittsburgh, Pittsburgh, PA 15260, USA. ²Department of Surgery, University of Pittsburgh School of Medicine, Pittsburgh, PA 15213, USA. ${ }^{3}$ Research and Development, Veterans Affairs Pittsburgh Healthcare System, Pittsburgh, PA 15240, USA. ${ }^{4}$ McGowan Institute for Regenerative Medicine, University of Pittsburgh, Pittsburgh, PA 15219, USA.

Received: 17 January 2018 Accepted: 5 March 2018

Published online: 27 March 2018

\section{References}

1. Kerr JF, Wyllie AH, Currie AR. Apoptosis: a basic biological phenomenon with wide-ranging implications in tissue kinetics. Br J Cancer. 1972;26:239-57.

2. Suzanne M, Steller H. Shaping organisms with apoptosis. Cell Death Differ. 2013;20:669-75.

3. Taylor RC, Cullen SP, Martin SJ. Apoptosis: controlled demolition at the cellular level. Nat Rev Mol Cell Biol. 2008;9:231-41.

4. Jorgensen I, Rayamajhi M, Miao EA. Programmed cell death as a defence against infection. Nat Rev Immunol. 2017;17:151-64.

5. Fuchs $Y$, Steller H. Programmed cell death in animal development and disease. Cell. 2011;147:742-58.

6. Vanden Berghe T, Hassannia B, Vandenabeele P. An outline of necrosome triggers. Cell Mol Life Sci. 2016;73:2137-52.

7. Dillon CP, Tummers B, Baran K, Green DR. Developmental checkpoints guarded by regulated necrosis. Cell Mol Life Sci. 2016;73:2125-36.

8. Dondelinger Y, Darding M, Bertrand MJ, Walczak H. Poly-ubiquitination in TNFR1-mediated necroptosis. Cell Mol Life Sci. 2016;73:2165-76.

9. Jorgensen I, Miao EA. Pyroptotic cell death defends against intracellular pathogens. Immunol Rev. 2015;265:130-42. 
10. Remijsen Q, Kuijpers TW, Wirawan E, Lippens S, Vandenabeele P, Vanden Berghe T. Dying for a cause: NETosis, mechanisms behind an antimicrobial cell death modality. Cell Death Differ. 2011;18:581-8.

11. Winters BD, Eberlein M, Leung J, Needham DM, Pronovost PJ, Sevransky JE. Long-term mortality and quality of life in sepsis: a systematic review. Crit Care Med. 2010;38:1276-83.

12. Ashbaugh $\mathrm{DG}$, Bigelow $\mathrm{DB}$, Petty $\mathrm{TL}$, Levine BE. Acute respiratory distress in adults. Lancet. 1967;2:319-23.

13. Faist $E$, Baue $A E$, Dittmer $H$, Heberer $G$. Multiple organ failure in polytrauma patients. J Trauma. 1983;23:775-87.

14. Fowler AA, Hamman RF, Good JT, Benson KN, Baird M, Eberle DJ, Petty TL, Hyers TM. Adult respiratory distress syndrome: risk with common predispositions. Ann Intern Med. 1983;98:593-7.

15. Martin WJ 2nd, Wu M, Pasula R. A novel approach to restore lung immunity during systemic immunosuppression. Trans Am Clin Climatol Assoc. 2005; 116:221-6. discussion 226-227

16. Murray PJ, Allen JE, Biswas SK, Fisher EA, Gilroy DW, Goerdt S, Gordon S, Hamilton JA, Ivashkiv LB, Lawrence T, et al. Macrophage activation and polarization: nomenclature and experimental guidelines. Immunity. 2014;41: 14-20.

17. Gordon S, Pluddemann A, Martinez Estrada F. Macrophage heterogeneity in tissues: phenotypic diversity and functions. Immunol Rev. 2014;262:36-55.

18. Rivera A, Siracusa MC, Yap GS, Gause WC. Innate cell communication kickstarts pathogen-specific immunity. Nat Immunol. 2016;17:356-63.

19. Coopersmith CM, Stromberg PE, Dunne WM, Davis CG, Amiot DM 2nd, Buchman TG, Karl IE, Hotchkiss RS. Inhibition of intestinal epithelial apoptosis and survival in a murine model of pneumonia-induced sepsis. JAMA. 2002;287:1716-21

20. Villar J, Sulemanji D, Kacmarek RM. The acute respiratory distress syndrome: incidence and mortality, has it changed? Curr Opin Crit Care. 2014;20:3-9.

21. Xu J, Jiang Y, Wang J, Shi X, Liu Q, Liu Z, Li Y, Scott MJ, Xiao G, Li S, et al. Macrophage endocytosis of high-mobility group box 1 triggers pyroptosis. Cell Death Differ. 2014;21:1229-39.

22. Li Z, Scott MJ, Fan EK, Li Y, Liu J, Xiao G, Li S, Billiar TR, Wilson MA, Jiang Y, Fan J. Tissue damage negatively regulates LPS-induced macrophage necroptosis. Cell Death Differ. 2016;23:1428-47.

23. Yang J, Zhao $Y$, Zhang $P$, Li Y, Yang $Y$, Zhu J, Song $X$, Jiang G, Fan J. Hemorrhagic shock primes for lung vascular endothelial cell pyroptosis: role in pulmonary inflammation following LPS. Cell Death Dis. 2016;7: e2363.

24. Linkermann A, Stockwell BR, Krautwald S, Anders HJ. Regulated cell death and inflammation: an auto-amplification loop causes organ failure. Nat Rev Immunol. 2014;14:759-67.

25. Kovacs SB, Miao EA. Gasdermins: effectors of Pyroptosis. Trends Cell Biol. 2017;

26. Shi J, Zhao Y, Wang K, Shi X, Wang Y, Huang H, Zhuang Y, Cai T, Wang F, Shao F. Cleavage of GSDMD by inflammatory caspases determines pyroptotic cell death. Nature. 2015;526:660-5.

27. von Moltke J, Ayres JS, Kofoed EM, Chavarria-Smith J, Vance RE. Recognition of bacteria by inflammasomes. Annu Rev Immunol. 2013;31:73-106.

28. Chae JJ, Cho YH, Lee GS, Cheng J, Liu PP, Feigenbaum L, Katz SI, Kastner DL. Gain-of-function pyrin mutations induce NLRP3 proteinindependent interleukin-1 beta activation and severe autoinflammation in mice. Immunity. 2011;34:755-68.

29. Latz E, Xiao TS, Stutz A. Activation and regulation of the inflammasomes. Nat Rev Immunol. 2013;13:397-411.

30. Jhang JJ, Cheng YT, Ho CY, Yen GC. Monosodium urate crystals trigger Nrf2and heme oxygenase-1-dependent inflammation in THP-1 cells. Cell Mol Immunol. 2015;12:424-34.

31. Franklin BS, Bossaller L, De Nardo D, Ratter JM, Stutz A, Engels G, Brenker C, Nordhoff M, Mirandola SR, Al-Amoudi A, et al. The adaptor ASC has extracellular and 'prionoid' activities that propagate inflammation. Nat Immunol. 2014;15:727-37.

32. Delaleu N, Bickel M. Interleukin-1 beta and interleukin-18: regulation and activity in local inflammation. Periodontol 2000. 2004;35:42-52.

33. Nakanishi $\mathrm{K}$, Yoshimoto T, Tsutsui H, Okamura H. Interleukin-18 regulates both Th1 and Th2 responses. Annu Rev Immunol. 2001;19:423-74.

34. Fink SL, Cookson BT. Caspase-1-dependent pore formation during pyroptosis leads to osmotic lysis of infected host macrophages. Cell Microbiol. 2006;8:1812-25.
35. Gurcel L, Abrami L, Girardin S, Tschopp J, van der Goot FG. Caspase-1 activation of lipid metabolic pathways in response to bacterial pore-forming toxins promotes cell survival. Cell. 2006;126:1135-45.

36. He X, Qian Y, Li Z, Fan EK, Li Y, Wu L, Billiar TR, Wilson MA, Shi X, Fan J. TLR4-upregulated IL-1 beta and IL-1RI promote alveolar macrophage Pyroptosis and lung inflammation through an autocrine mechanism. Sci Rep. 2016;6:31663.

37. Xiang M, Shi X, Li Y, Xu J, Yin L, Xiao G, Scott MJ, Billiar TR, Wilson MA, Fan J. Hemorrhagic shock activation of NLRP3 Inflammasome in lung endothelial cells. J Immunol. 2011;187:4809-17.

38. Roumen RM, Hendriks T, Van der Ven-Jongekrijg J, Nieuwenhuijzen GA, Sauerwein RW, van der Meer JW, Goris RJ. Cytokine patterns in patients after major vascular surgery, hemorrhagic shock, and severe blunt trauma. Relation with subsequent adult respiratory distress syndrome and multiple organ failure. Ann Surg. 1993;218:769-76.

39. Roumen RM, Redl H, Schlag G, Zilow G, Sandtner W, Koller W, Hendriks T, Goris RJ. Inflammatory mediators in relation to the development of multiple organ failure in patients after severe blunt trauma. Crit Care Med. 1995;23: 474-80.

40. Zhu XL, Zellweger R, Zhu XH, Ayala A, Chaudry $\Vdash H$. Cytokine gene expression in splenic macrophages and Kupffer cells following haemorrhage. Cytokine. 1995;7:8-14.

41. Shenkar R, Abraham E. Effects of hemorrhage on cytokine gene transcription. Lymphokine Cytokine Res. 1993;12:237-47.

42. Shenkar R, Coulson WF, Abraham E. Hemorrhage and resuscitation induce alterations in cytokine expression and the development of acute lung injury. Am J Respir Cell Mol Biol. 1994;10:290-7.

43. Abraham E, Richmond NJ, Chang YH. Effects of hemorrhage on interleukin1 production. Circ Shock. 1988;25:33-40.

44. Xu P, Wen Z, Shi X, Li Y, Fan L, Xiang M, Li A, Scott MJ, Xiao G, Li S, et al. Hemorrhagic shock augments Nlrp3 inflammasome activation in the lung through impaired pyrin induction. J Immunol. 2013;190:5247-55.

45. Papin S, Cuenin S, Agostini L, Martinon F, Werner S, Beer HD, Grutter C, Grutter M, Tschopp J. The SPRY domain of pyrin, mutated in familial Mediterranean fever patients, interacts with inflammasome components and inhibits proll-1 beta processing. Cell Death Differ. 2007;14:1457-66.

46. Martinon F, Hofmann K, Tschopp J. The pyrin domain: a possible member of the death domain-fold family implicated in apoptosis and inflammation. Curr Biol. 2001;11:R118-20.

47. Staub E, Dahl E, Rosenthal A. The DAPIN family: a novel domain links apoptotic and interferon response proteins. Trends Biochem Sci. 2001;26: 83-5.

48. Fan J, Li Y, Vodovotz Y, Billiar TR, Wilson MA. Hemorrhagic shock-activated neutrophils augment TLR4 signaling-induced TLR2 upregulation in alveolar macrophages: role in hemorrhage-primed lung inflammation. Am J Physiol Lung Cell Mol Physiol. 2006;290:L738-46.

49. Fan J, Li Y, Vodovotz Y, Billiar TR, Wilson MA. Neutrophil NAD(P)H oxidase is required for hemorrhagic shock-enhanced TLR2 up-regulation in alveolar macrophages in response to LPS. Shock. 2007;28:213-8.

50. Fan J, Marshall JC, Jimenez M, Shek PN, Zagorski J, Rotstein OD. Hemorrhagic shock primes for increased expression of cytokine-induced neutrophil chemoattractant in the lung: role in pulmonary inflammation following lipopolysaccharide. J Immunol. 1998;161:440-7.

51. Lotze MT, Tracey KJ. High-mobility group box 1 protein (HMGB1): nuclear weapon in the immune arsenal. Nat Rev Immunol. 2005;5:331-42.

52. Wang H, Yang H, Czura CJ, Sama AE, Tracey KJ. HMGB1 as a late mediator of lethal systemic inflammation. Am J Respir Crit Care Med. 2001;164:1768-73.

53. Yang $H$, Wang $H$, Czura $C J$, Tracey KJ. The cytokine activity of HMGB1. J Leukoc Biol. 2005;78:1-8

54. Lu B, Nakamura T, Inouye K, Li J, Tang Y, Lundback P, Valdes-Ferrer SI, Olofsson PS, Kalb T, Roth J, et al. Novel role of PKR in inflammasome activation and HMGB1 release. Nature. 2012;488:670-4.

55. Andersson $\mathrm{U}$, Tracey KJ. HMGB1 is a therapeutic target for sterile inflammation and infection. Annu Rev Immunol. 2011;29:139-62.

56. Mollen KP, Anand RJ, Tsung A, Prince JM, Levy RM, Billiar TR. Emerging paradigm: toll-like receptor 4-sentinel for the detection of tissue damage. Shock. 2006:26:430-7.

57. Martinon F, Petrilli V, Mayor A, Tardivel A, Tschopp J. Gout-associated uric acid crystals activate the NALP3 inflammasome. Nature. 2006;440: 237-41. 
58. Cullen SP, Kearney CJ, Clancy DM, Martin SJ. Diverse activators of the NLRP3 Inflammasome promote IL-1beta secretion by triggering necrosis. Cell Rep. 2015;11:1535-48

59. Martin-Sanchez F, Martinez-Garcia JJ, Munoz-Garcia M, Martinez-Villanueva M, Noguera-Velasco JA, Andreu D, Rivas L, Pelegrin P. Lytic cell death induced by melittin bypasses pyroptosis but induces NLRP3 inflammasome activation and IL-1 beta release. Cell Death Dis. 2017;8:e2984.

60. Yang $Y$, Jiang G, Zhang P, Fan J. Programmed cell death and its role in inflammation. Mil Med Res. 2015;2:12.

61. Galluzzi L, Vitale I, Abrams JM, Alnemri ES, Baehrecke EH, Blagosklonny MV, Dawson TM, Dawson VL, El-Deiry WS, Fulda S, et al. Molecular definitions of cell death subroutines: recommendations of the nomenclature committee on cell death 2012. Cell Death Differ. 2012;19:107-20.

62. Andera $L$. Signaling activated by the death receptors of the TNFR family. Biomed Pap Med Fac Univ Palacky Olomouc Czech Repub. 2009;153:173-80.

63. Wertz IE, Dixit VM. Ubiquitin-mediated regulation of TNFR1 signaling. Cytokine Growth Factor Rev. 2008;19:313-24

64. O'Donnell MA, Legarda-Addison D, Skountzos P, Yeh WC, Ting AT. Ubiquitination of RIP1 regulates an NF-kappaB-independent cell-death switch in TNF signaling. Curr Biol. 2007;17:418-24.

65. Feoktistova M, Geserick P, Kellert B, Dimitrova DP, Langlais C, Hupe M, Cain K, MacFarlane M, Hacker G, Leverkus M. cIAPs block Ripoptosome formation, a RIP1/caspase-8 containing intracellular cell death complex differentially regulated by cFLIP isoforms. Mol Cell. 2011;43:449-63.

66. Bertrand MJ, Milutinovic S, Dickson KM, Ho WC, Boudreault A, Durkin J, Gillard JW, Jaquith JB, Morris SJ, Barker PA. CIAP1 and CIAP2 facilitate cancer cell survival by functioning as E3 ligases that promote RIP1 ubiquitination. Mol Cell. 2008;30:689-700.

67. Declercq W, Vanden Berghe T, Vandenabeele P. RIP kinases at the crossroads of cell death and survival. Cell. 2009:138:229-32.

68. Sun L, Wang H, Wang Z, He S, Chen S, Liao D, Wang L, Yan J, Liu W, Lei X, Wang $X$. Mixed lineage kinase domain-like protein mediates necrosis signaling downstream of RIP3 kinase. Cell. 2012;148:213-27.

69. Zhao J, Jitkaew S, Cai Z, Choksi S, Li Q, Luo J, Liu ZG. Mixed lineage kinase domain-like is a key receptor interacting protein 3 downstream component of TNF-induced necrosis. Proc Natl Acad Sci U S A. 2012;109:5322-7.

70. Orozco S, Yatim N, Werner MR, Tran H, Gunja SY, Tait SW, Albert ML, Green DR, Oberst A. RIPK1 both positively and negatively regulates RIPK3 oligomerization and necroptosis. Cell Death Differ. 2014;21:1511-21.

71. Wu XN, Yang ZH, Wang XK, Zhang $Y$, Wan H, Song Y, Chen X, Shao J, Han J. Distinct roles of RIP1-RIP3 hetero- and RIP3-RIP3 homo-interaction in mediating necroptosis. Cell Death Differ. 2014;21:1709-20.

72. Murphy JM, Czabotar PE, Hildebrand JM, Lucet IS, Zhang JG, Alvarez-Diaz S, Lewis $\mathrm{R}$, Lalaoui N, Metcalf D, Webb Al, et al. The pseudokinase MLKL mediates necroptosis via a molecular switch mechanism. Immunity. 2013;39: 443-53

73. Kaiser WJ, Sridharan H, Huang C, Mandal P, Upton JW, Gough PJ, Sehon CA Marquis RW, Bertin J, Mocarski ES. Toll-like receptor 3-mediated necrosis via TRIF, RIP3, and MLKL. J Biol Chem. 2013;288:31268-79.

74. Galluzzi L, Vitale I, Aaronson SA, Abrams JM, Adam D, Agostinis P, Alnemri ES, Altucci L, Amelio I, Andrews DW, et al. Molecular mechanisms of cell death: recommendations of the Nomenclature Committee on Cell Death 2018. Cell Death Differ. 2018;25(3):486-541.

75. Thapa RJ, Nogusa S, Chen P, Maki JL, Lerro A, Andrake M, Rall GF, Degterev A, Balachandran S. Interferon-induced RIP1/RIP3-mediated necrosis requires PKR and is licensed by FADD and caspases. Proc Natl Acad Sci U S A. 2013; 110:E3109-18.

76. Upton JW, Kaiser WJ, Mocarski ES. DAI/ZBP1/DLM-1 complexes with RIP3 to mediate virus-induced programmed necrosis that is targeted by murine cytomegalovirus vIRA. Cell Host Microbe. 2012;11:290-7.

77. Chen X, Li W, Ren J, Huang D, He WT, Song Y, Yang C, Li W, Zheng X, Chen $P$, Han J. Translocation of mixed lineage kinase domain-like protein to plasma membrane leads to necrotic cell death. Cell Res. 2014;24:105-21.

78. Pasparakis M, Vandenabeele P. Necroptosis and its role in inflammation. Nature. 2015:517:311-20.

79. He S, Wang L, Miao L, Wang T, Du F, Zhao L, Wang X. Receptor interacting protein kinase-3 determines cellular necrotic response to TNF-alpha. Cell. 2009;137:1100-11.

80. Welz PS, Wullaert A, Vlantis K, Kondylis V, Fernandez-Majada V, Ermolaeva M, Kirsch P, Sterner-Kock A, van Loo G, Pasparakis M. FADD prevents RIP3- mediated epithelial cell necrosis and chronic intestinal inflammation. Nature. 2011;477:330-4.

81. Wang H, Sun L, Su L, Rizo J, Liu L, Wang LF, Wang FS, Wang X. Mixed lineage kinase domain-like protein MLKL causes necrotic membrane disruption upon phosphorylation by RIP3. Mol Cell. 2014;54:133-46.

82. Rickard JA, O'Donnell JA, Evans JM, Lalaoui N, Poh AR, Rogers T, Vince JE, Lawlor KE, Ninnis RL, Anderton H, et al. RIPK1 regulates RIPK3-MLKLdriven systemic inflammation and emergency hematopoiesis. Cell. 2014; 157:1175-88.

83. Lin J, Li H, Yang M, Ren J, Huang Z, Han F, Huang J, Ma J, Zhang D, Zhang $Z$, et al. A role of RIP3-mediated macrophage necrosis in atherosclerosis development. Cell Rep. 2013;3:200-10.

84. Colbert LE, Fisher SB, Hardy CW, Hall WA, Saka B, Shelton JW, Petrova AV, Warren MD, Pantazides BG, Gandhi K, et al. Pronecrotic mixed lineage kinase domain-like protein expression is a prognostic biomarker in patients with early-stage resected pancreatic adenocarcinoma. Cancer. 2013;119:3148-55.

85. Dondelinger Y, Aguileta MA, Goossens V, Dubuisson C, Grootjans S, Dejardin E, Vandenabeele P, Bertrand MJ. RIPK3 contributes to TNFR1-mediated RIPK1 kinase-dependent apoptosis in conditions of CIAP1/2 depletion or TAK1 kinase inhibition. Cell Death Differ. 2013;20:1381-92.

86. Kaiser WJ, Upton JW, Long AB, Livingston-Rosanoff D, Daley-Bauer LP, Hakem R, Caspary T, Mocarski ES. RIP3 mediates the embryonic lethality of caspase-8-deficient mice. Nature. 2011;471:368-72.

87. Zhang H, Zhou X, McQuade T, Li J, Chan FK, Zhang J. Functional complementation between FADD and RIP1 in embryos and lymphocytes. Nature. 2011;471:373-6.

88. Oberst A, Dillon CP, Weinlich R, McCormick LL, Fitzgerald P, Pop C, Hakem R, Salvesen GS, Green DR. Catalytic activity of the caspase-8-FLIP $(L)$ complex inhibits RIPK3-dependent necrosis. Nature. 2011;471:363-7.

89. Bonnet MC, Preukschat D, Welz PS, van Loo G, Ermolaeva MA, Bloch W, Haase I, Pasparakis M. The adaptor protein FADD protects epidermal keratinocytes from necroptosis in vivo and prevents skin inflammation. Immunity. 2011;35:572-82.

90. Dannappel M, Vlantis K, Kumari S, Polykratis A, Kim C, Wachsmuth L, Eftychi C, Lin J, Corona T, Hermance N, et al. RIPK1 maintains epithelial homeostasis by inhibiting apoptosis and necroptosis. Nature. 2014;513:90-4.

91. Dillon CP, Weinlich R, Rodriguez DA, Cripps JG, Quarato G, Gurung P, Verbist KC, Brewer TL, Llambi F, Gong YN, et al. RIPK1 blocks early postnatal lethality mediated by caspase-8 and RIPK3. Cell. 2014;157:1189-202.

92. Kaiser WJ, Daley-Bauer LP, Thapa RJ, Mandal P, Berger SB, Huang C, Sundararajan A, Guo H, Roback L, Speck SH, et al. RIP1 suppresses innate immune necrotic as well as apoptotic cell death during mammalian parturition. Proc Natl Acad Sci U S A. 2014;111:7753-8.

93. Takahashi N, Vereecke L, Bertrand MJ, Duprez L, Berger SB, Divert T, Goncalves A, Sze M, Gilbert B, Kourula S, et al. RIPK1 ensures intestinal homeostasis by protecting the epithelium against apoptosis. Nature. 2014; 513:95-9.

94. Lin J, Kumari S, Kim C, Van TM, Wachsmuth L, Polykratis A, Pasparakis M. RIPK1 counteracts ZBP1-mediated necroptosis to inhibit inflammation. Nature. 2016;540:124-8.

95. Newton K, Wickliffe KE, Maltzman A, Dugger DL, Strasser A, Pham VC, Lill JR, Roose-Girma M, Warming S, Solon M, et al. RIPK1 inhibits ZBP1-driven necroptosis during development. Nature. 2016;540:129-33.

96. Li Z, Fan EK, Liu J, Scott MJ, Li Y, Li S, Xie W, Billiar TR, Wilson MA, Jiang Y, et al. Cold-inducible RNA-binding protein through TLR4 signaling induces mitochondrial DNA fragmentation and regulates macrophage cell death after trauma. Cell Death Dis. 2017;8:e2775.

97. Nishiyama H, Higashitsuji H, Yokoi H, Itoh K, Danno S, Matsuda T, Fujita J. Cloning and characterization of human CIRP (cold-inducible RNA-binding protein) cDNA and chromosomal assignment of the gene. Gene. 1997;204: 115-20.

98. Hea N. A glycine-rich RNA-binding protein mediating cold-inducible suppression of mammalian cell growth. J Cell Biol. 1997;137:899-908.

99. Morf J, Rey G, Schneider K, Stratmann M, Fujita J, Naef F, Schibler U. Coldinducible RNA-binding protein modulates circadian gene expression posttranscriptionally. Science. 2012;338:379-83.

100. Lord JM, Midwinter MJ, Chen YF, Belli A, Brohi K, Kovacs EJ, Koenderman L, Kubes $P$, Lilford RJ. The systemic immune response to trauma: an overview of pathophysiology and treatment. Lancet. 2014;384:1455-65.

101. Qiang $X$, Yang WL, Wu R, Zhou M, Jacob A, Dong W, Kuncewitch M, Ji Y, Yang $\mathrm{H}$, Wang $\mathrm{H}$, et al. Cold-inducible RNA-binding protein (CIRP) triggers 
inflammatory responses in hemorrhagic shock and sepsis. Nat Med. 2013;19: 1489-95.

102. Fan J, Li Y, Levy RM, Fan JJ, Hackam DJ, Vodovotz Y, Yang H, Tracey KJ, Billiar TR, Wilson MA. Hemorrhagic shock induces NAD(P)H oxidase activation in neutrophils: role of HMGB1-TLR4 signaling. J Immunol. 2007; 178:6573-80.

103. Wen Z, Fan L, Li Y, Zou Z, Scott MJ, Xiao G, Li S, Billiar TR, Wilson MA, Shi X, Fan J. Neutrophils counteract autophagy-mediated anti-inflammatory mechanisms in alveolar macrophage: role in posthemorrhagic shock acute lung inflammation. J Immunol. 2014;193:4623-33.

104. Duprez L, Takahashi N, Van Hauwermeiren F, Vandendriessche B, Goossens V, Vanden Berghe T, Declercq W, Libert C, Cauwels A, Vandenabeele P. RIP kinase-dependent necrosis drives lethal systemic inflammatory response syndrome. Immunity. 2011;35:908-18.

105. Wu J, Huang Z, Ren J, Zhang Z, He P, Li Y, Ma J, Chen W, Zhang Y, Zhou X, et al. Mlkl knockout mice demonstrate the indispensable role of Mlkl in necroptosis. Cell Res. 2013;23:994-1006.

106. Conrad M, Angeli JP, Vandenabeele P, Stockwell BR. Regulated necrosis: disease relevance and therapeutic opportunities. Nat Rev Drug Discov. 2016; 15:348-66.

107. Takahashi N, Duprez L, Grootjans S, Cauwels A, Nerinckx W, DuHadaway JB, Goossens V, Roelandt R, Van Hauwermeiren F, Libert C, et al. Necrostatin-1 analogues: critical issues on the specificity, activity and in vivo use in experimental disease models. Cell Death Dis. 2012;3:e437.

108. Newton K, Dugger DL, Wickliffe KE, Kapoor N, de Almagro MC, Vucic D, Komuves L, Ferrando RE, French DM, Webster J, et al. Activity of protein kinase RIPK3 determines whether cells die by necroptosis or apoptosis. Science. 2014;343:1357-60.

109. Polykratis A, Hermance N, Zelic M, Roderick J, Kim C, Van TM, Lee TH, Chan FKM, Pasparakis M, Kelliher MA. Cutting edge: RIPK1 kinase inactive mice are viable and protected from TNF-induced necroptosis in vivo. J Immunol. 2014;193:1539-43.

110. Eskelinen EL, Saftig P. Autophagy: a lysosomal degradation pathway with a central role in health and disease. Biochim Biophys Acta. 2009;1793:664-73.

111. Ravikumar B, Sarkar S, Davies JE, Futter M, Garcia-Arencibia M, GreenThompson ZW, Jimenez-Sanchez M, Korolchuk VI, Lichtenberg M, Luo S, et al. Regulation of mammalian autophagy in physiology and pathophysiology. Physiol Rev. 2010;90:1383-435.

112. Shimizu S, Kanaseki T, Mizushima N, Mizuta T, Arakawa-Kobayashi S, Thompson CB, Tsujimoto Y. Role of BCl-2 family proteins in a non-apoptotic programmed cell death dependent on autophagy genes. Nat Cell Biol. 2004:6:1221-8.

113. Kroemer G, Levine B. Autophagic cell death: the story of a misnomer. Nat Rev Mol Cell Biol. 2008;9:1004-10

114. Shen HM, Codogno P. Autophagic cell death: loch ness monster or endangered species? Autophagy. 2011;7:457-65.

115. Yang J, Carra S, Zhu WG, Kampinga HH. The regulation of the autophagic network and its implications for human disease. Int J Biol Sci. 2013;9:1121-33.

116. Shibutani ST, Saitoh T, Nowag H, Munz C, Yoshimori T. Autophagy and autophagy-related proteins in the immune system. Nat Immunol. 2015;16: 1014-24.

117. Parzych KR, Klionsky DJ. An overview of autophagy: morphology, mechanism, and regulation. Antioxid Redox Signal. 2014;20:460-73.

118. Xu Y, Jagannath C, Liu XD, Sharafkhaneh A, Kolodziejska KE, Eissa NT. Tolllike receptor 4 is a sensor for autophagy associated with innate immunity. Immunity. 2007;27:135-44.

119. Delgado MA, Elmaoued RA, Davis AS, Kyei G, Deretic V. Toll-like receptors control autophagy. EMBO J. 2008;27:1110-21.

120. Travassos LH, Carneiro LA, Girardin S, Philpott DJ. Nod proteins link bacterial sensing and autophagy. Autophagy. 2010;6:409-11.

121. Cooney R, Baker J, Brain O, Danis B, Pichulik T, Allan P, Ferguson DJ, Campbell BJ, Jewell D, Simmons A. NOD2 stimulation induces autophagy in dendritic cells influencing bacterial handling and antigen presentation. Nat Med. 2010;16:90-7.

122. Harris J, Hartman M, Roche C, Zeng SG, O'Shea A, Sharp FA, Lambe EM, Creagh EM, Golenbock DT, Tschopp J, et al. Autophagy controls IL-1 beta secretion by targeting pro-IL-1 beta for degradation. J Biol Chem. 2011;286: 9587-97.

123. Shi CS, Shenderov K, Huang NN, Kabat J, Abu-Asab M, Fitzgerald KA, Sher A, Kehrl JH. Activation of autophagy by inflammatory signals limits IL-1 beta production by targeting ubiquitinated inflammasomes for destruction. Nat Immunol. 2012;13:255-63.

124. Gutierrez MG, Master SS, Singh SB, Taylor GA, Colombo MI, Deretic V. Autophagy is a defense mechanism inhibiting BCG and Mycobacterium tuberculosis survival in infected macrophages. Cell. 2004;119:753-66.

125. Harris J, De Haro SA, Master SS, Keane J, Roberts EA, Delgado M, Deretic V. T helper 2 cytokines inhibit autophagic control of intracellular Mycobacterium tuberculosis. Immunity. 2007;27:505-17.

126. Singh SB, Ornatowski W, Vergne I, Naylor J, Delgado M, Roberts E, Ponpuak M, Master S, Pilli M, White E, et al. Human IRGM regulates autophagy and cell-autonomous immunity functions through mitochondria. Nat Cell Biol. 2010;12:1154-65.

127. Schmid D, Munz C. Innate and adaptive immunity through autophagy. Immunity. 2007;27:11-21.

128. Rubinsztein DC, Codogno P, Levine B. Autophagy modulation as a potential therapeutic target for diverse diseases. Nat Rev Drug Discov. 2012;11:709-30.

129. Johansen T, Lamark T. Selective autophagy mediated by autophagic adapter proteins. Autophagy. 2011;7:279-96.

130. Fan T, Chen L, Huang Z, Mao Z, Wang W, Zhang B, Xu Y, Pan S, Hu H, Geng Q. Autophagy decreases alveolar macrophage apoptosis by attenuating endoplasmic reticulum stress and oxidative stress. Oncotarget. 2016;7: 87206-18.

131. Liu X, Cao H, Li J, Wang B, Zhang P, Dong Zhang X, Liu Z, Yuan H, Zhan Z. Autophagy induced by DAMPs facilitates the inflammation response in lungs undergoing ischemia-reperfusion injury through promoting TRAF6 ubiquitination. Cell Death Differ. 2017:24:683-93.

132. Fan J, Frey RS, Malik AB. TLR4 signaling induces TLR2 expression in endothelial cells via neutrophil NADPH oxidase. J Clin Invest. 2003;112: 1234-43.

133. Yang Jiao ZL, Loughran PA, Fan EK, Scott MJ, TRB YL, Wilson MA, Shi X, Fan J. Macrophage-Derived Exosomes Promote Neutrophil Necroptosis Following Hemorrhagic Shock. J Leukoc Biol. 2017; https://doi.org/10.1189/ jlb.3HI0517-173R. [Epub ahead of print]

134. Simons M, Raposo G. Exosomes-vesicular carriers for intercellular communication. Curr Opin Cell Biol. 2009;21:575-81.

135. de Jong OG, Verhaar MC, Chen Y, Vader P, Gremmels H, Posthuma G, Schiffelers RM, Gucek M, van Balkom BW. Cellular stress conditions are reflected in the protein and RNA content of endothelial cell-derived exosomes. J Extracell Vesicles. 2012;1

136. Fevrier B, Vilette D, Archer F, Loew D, Faigle W, Vidal M, Laude H, Raposo G. Cells release prions in association with exosomes. Proc Natl Acad Sci U S A. 2004;101:9683-8.

137. Wang $X$, Yousefi S, Simon HU. Necroptosis and neutrophil-associated disorders. Cell Death Dis. 2018;9:111.

138. Wang X, He Z, Liu H, Yousefi S, Simon HU. Neutrophil necroptosis is triggered by ligation of adhesion molecules following GM-CSF priming. J Immunol. 2016;197:4090-100.

139. Weinlich R, Oberst A, Beere HM, Green DR. Necroptosis in development, inflammation and disease. Nat Rev Mol Cell Biol. 2017;18:127-36.

140. Linkermann A, Brasen JH, Darding M, Jin MK, Sanz AB, Heller JO, De Zen F, Weinlich R, Ortiz A, Walczak H, et al. Two independent pathways of regulated necrosis mediate ischemia-reperfusion injury. Proc Natl Acad Sci U S A. 2013;110:12024-9.

141. Linkermann A, Brasen JH, Himmerkus N, Liu S, Huber TB, Kunzendorf U, Krautwald S. Rip1 (receptor-interacting protein kinase 1) mediates necroptosis and contributes to renal ischemia/reperfusion injury. Kidney Int. 2012;81:751-61.

142. Cho YS, Challa S, Moquin D, Genga R, Ray TD, Guildford M, Chan FK. Phosphorylation-driven assembly of the RIP1-RIP3 complex regulates programmed necrosis and virus-induced inflammation. Cell. 2009;137:1112-23.

143. Doitsh G, Galloway NL, Geng X, Yang Z, Monroe KM, Zepeda O, Hunt PW, Hatano H, Sowinski S, Munoz-Arias I, Greene WC. Cell death by pyroptosis drives CD4 T-cell depletion in HIV-1 infection. Nature. 2014;505:509-14. 